\title{
Respiratory motion navigated Look-Locker imaging for small animal myocardial T1mapping
}

\author{
Pan-ki Kim*, Joonsung Lee, Byoung Wook Choi \\ From 18th Annual SCMR Scientific Sessions \\ Nice, France. 4-7 February 2015
}

\section{Background}

The quantification of $\mathrm{T} 1$ relaxation time has become an important indicator for diffuse cardiomyopathies. In small animal studies, such as mouse and rat, fast heart beats and respiratory rates are major obstacles to use clinical $\mathrm{T} 1$ mapping methods. For small animal T1 mapping, SALLI (Messroghli DR et al., 2011) and mCINE-IR(Smit H et al., 2014) had been reported using the Look-Locker scheme. Since the Look-Locker recovery evolution has to be consistently maintained, the respiratory gating is particularly challenging. In general, the multiple averages were applied to avoid motion artifacts. In this study, respiratory motion navigated Look-Locker imaging (NALLI) was proposed to overcome respiratory motion artifacts for small animal myocardial T1 mapping. To evaluate feasibility, the proposed method was performed for phantoms and a normal mouse.

\section{Methods}

All MR studies were carried out on a 9.4 Tesla MRI (Bruker, Germany). The use of a mouse $(\mathrm{C} 57 \mathrm{BL} / 6)$ was approved by Institutional Animal Care and Use Committee (IACUC). NALLI was employed the Look-Locker scheme with navigator at the beginning of cardiac cycles as illustrated in Fig. 1. The navigators measured MR signals at the center of $\mathrm{k}$-space to detect motion-corrupted cardiac cycles. The echoes at the motion-corrupted cardiac cycle were replaced by the average of echoes at adjacent cardiac cycles. Look-Locker correction were applied at each pixel. In phantom studies, the NALLI was tested using eight phantoms doped with different amounts of a Gd-DOTA (DOTAREM, Guerbet). The phantoms were attached to an airbag, which inflated and deflated alternately to mimic respiratory motion. Imaging parameters were as follows: acquisition duration $=20$ cardiac cycles,

Yonsei University, Seoul, Korea, the Republic of relaxation duration $=2000 \mathrm{~ms}, 13$ cardiac phases, 3 slices, $\mathrm{TR} / \mathrm{TE}=12 / 1.25 \mathrm{~ms}, \mathrm{FA}=10^{\circ}, \mathrm{FOV}=3 \times 2 \mathrm{~cm}$, matrix $=$ $128 \times 86,0.23 \times 0.23$ pixel size, slice thickness $=1.5 \mathrm{~mm}$, $300 \mathrm{BPM}$ and $42 \mathrm{RPM}$. A normal mouse myocardium was scanned under anesthesia with isoflurane. Imaging parameters were same as phantom studies except slice thickness $=1.0 \mathrm{~mm}$. The NALLI and conventional LookLocker imaging (CLL) with multiple averaging were compared to evaluate the motion resistance by measuring $\mathrm{T} 1$ value and heterogeneity, defined as coefficient of variations of $\mathrm{T} 1$ value, on region of interests.

\section{Results}

In Fig. 2(a, b), T1 accuracies on moving phantoms were shown as percentage error from stationary phantoms. The NALLI as a mean error of $-1.34 \%$ has higher

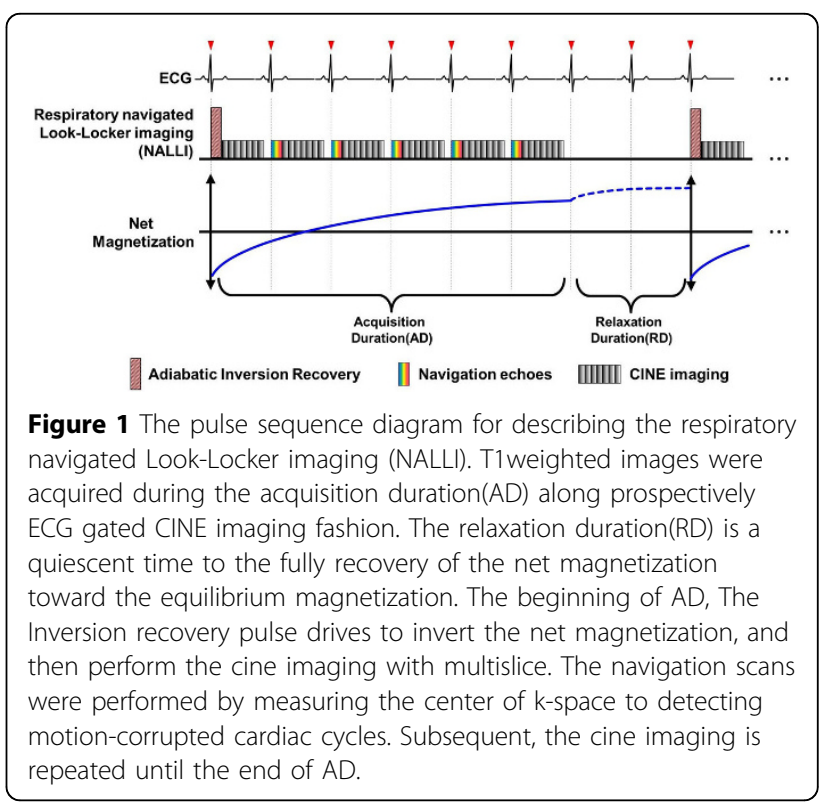


(a)

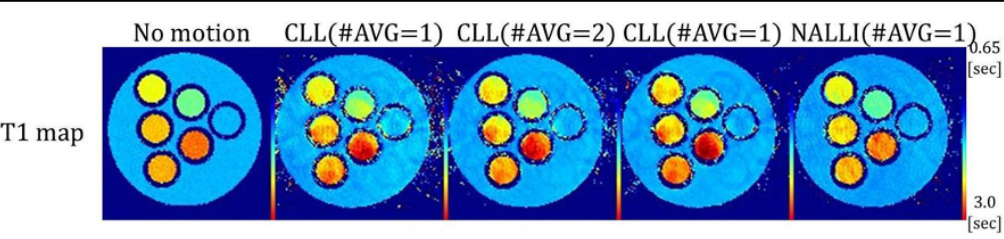

(b)

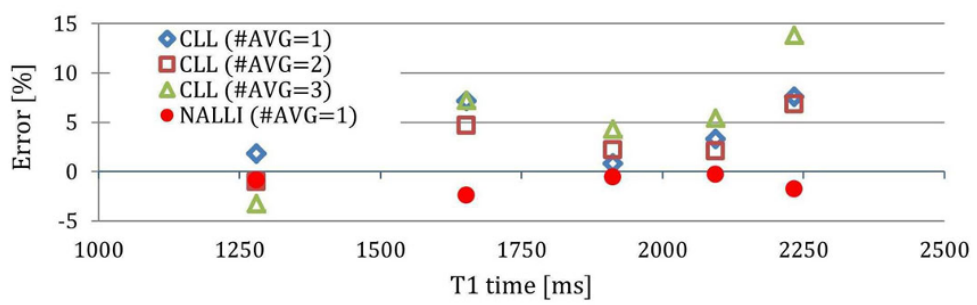

(c)
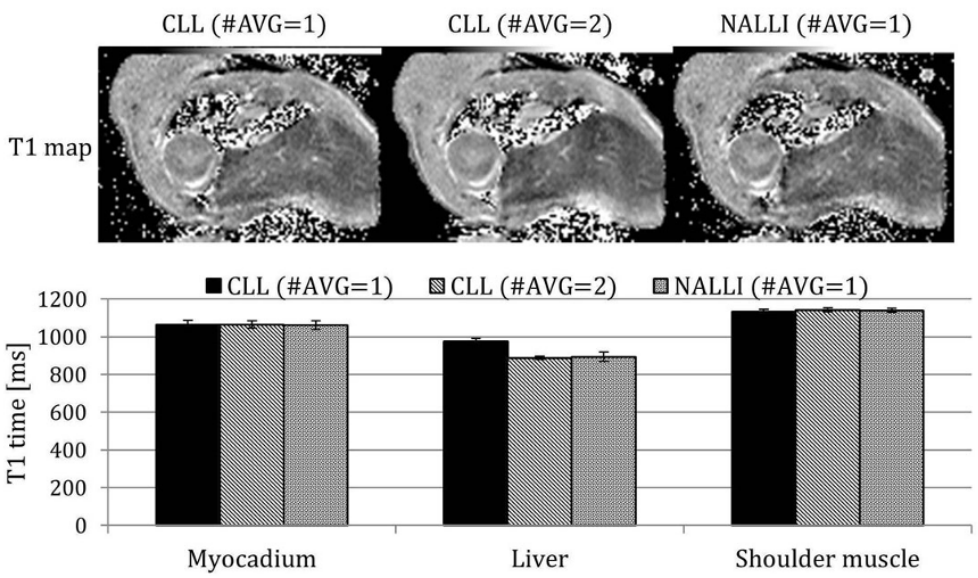

Figure $2 \mathrm{~T} 1$ maps and its measurements on phantoms and a mouse. (a) T1 maps using the NALLI and conventional Look-Locker (CLL) with multiple averages on stationary and moving phantom, (b) graphs show accuracy between the NALLI and CLL with difference average on moving phantom. Accuracy is expressed as percentage T1 error from stationary phantom, (c) T1 maps and (d) T1 value on invivo mouse. The T1 map of NALLI and CLL with average 2 have similar T1 values on all ROls. However, the T1 value of CLL with average 1 has overestimate than the others on liver.

accuracy than CLL with multiple averaging on moving phantom. The heterogeneities of NALLI and CLL with average 3 were $3.1 \%$ and $3.7 \%$, respectively. The NALLI has been shown as effective as using 3 averages within 1 average time. In fig. 2(c, d), the NALLI and CLL with average 2 produced similar T1 values on all ROI, but T1 maps using CLL with average 1 were overestimated over liver.

\section{Conclusions}

The proposed NALLI method can be provided the higher motion robustness and accuracy T1 map for small animal myocardium without additional measurement required

\section{Funding}

N/A.
doi:10.1186/1532-429X-17-S1-P20

Cite this article as: Kim et al.: Respiratory motion navigated Look-Locker imaging for small animal myocardial T1mapping. Journal of Cardiovascular Magnetic Resonance 2015 17(Suppl 1):P20.
Submit your next manuscript to BioMed Central and take full advantage of:

- Convenient online submission

- Thorough peer review

- No space constraints or color figure charges

- Immediate publication on acceptance

- Inclusion in PubMed, CAS, Scopus and Google Scholar

- Research which is freely available for redistribution 